\title{
Value at Risk, Legislative Framework, Crises, and Procyclicality: what goes wrong?
}

\author{
EVANGELOS VASILEIOU \\ University of the Aegean, School of Engineering \\ Department of Financial and Management Engineering* \\ ARISTEIDIS SAMITAS \\ Zayed University College of Business
}

\begin{abstract}
This study highlights some deficiencies of the stock markets' risk legislation framework, and particularly the CESR (2010) guidelines. We show that the current legislative framework fails to offer incentives to financial management companies to invest in advanced models for more representative Value at Risk (VaR) estimations, and for this reason, in many cases conventional VaR models are applied. We use data from the DAX, CAC 40, FTSE, FTSEMIB and IBEX indices, and then we apply them to the widely accepted Delta Normal VaR model. The empirical findings show that the conventional $\mathrm{VaR}$ models not only fail to provide information for the upcoming financial crises, but also contribute to such phenomena as procyclicality and overreaction in the stock market. We suggest additional tests and we empirically show how these tests could reduce the procyclicality issue and promote a more sustainable investment environment. Even though this study is mainly focused on CESR (2010) guidelines, it could be useful for any similar legislative framework, such as the Basel Accords.
\end{abstract}

Keywords: Financial regulation; Value at Risk; Procyclicality

JEL Classifications: G01, G17, G20, G28

\section{Introduction}

It is widely known that a robust financial system significantly contributes to economic growth (Beck, Levine and Loayza (2000)). In order to achieve this, one of the financial system's primary roles is to efficiently allocate resources from savers to borrowers/enterprises and in order for the intermediation procedure to work efficiently, the financial system should allow risk to be shared (Allen, Chui, and Maddaloni (2004)). Therefore, a reliable risk measure is crucial for the financial system's robustness and for economic growth.

\footnotetext{
* Evangelos: Assistant Professor, E-mail: e.vasileiou@ba.aegean.gr; Samitas: Professor of Finance, Abu Dhabi - Khalifa City, Email: Aristeidis.Samitas@zu.ac.ae

(C) 2020 Vasileiou Evangelos and Aristeidis Samitas. Licensed under the Creative Commons Attribution - Noncommercial 3.0 Licence (http://creativecommons.org/licenses/by-nc/3.0/. Available at http: //rofea.org.
} 
Value at Risk (VaR) is assumed to be the main risk estimation measure in the financial industry. Accurate VaR estimations have puzzled financial economists, scholars, practitioners and regulators over the last decades and that is why the financial literature is mainly focused on VaR modeling. However, even though many advanced econometric methodologies have been suggested for the estimation of systematic risk (Engle and Manganelli (2004), Liu and Tse (2015), Billio and Pelizzon (2000), Moussa, Kamdem and Terraza (2014), Zhang, Su, Song, Qiu, Xiao and $\mathrm{Su}$ (2017)), several financial crises emerged in the same period throughout the world (Reinhart and Rogoff (2008)). Why does this happen?

Prominent scholars have noticed that the contemporary financial models use so complex equations that non-mathematicians find them incomprehensible (Fama (1995)), and that often these models appear to be torturing the data in order to confess the crime/accurate estimations (Ross (1993)). Some other scholars observe that the advanced models are not widely applied in the financial industry due to the aforementioned complexity issue and the increased implementation costs that these models involve (Vasileiou (2016)). Could some of the crises have been avoided if such advanced models were adopted and used in real life? Could some legislative interventions force UCITS companies to adopt models that produce more reliable and representative VaR estimations?

In this paper we do not try to present a new model, but to stress some deficiencies of the legislative framework, particularly concerning the Committtee of European Securities Regulators Guidelines on Risk Measurement for $\operatorname{UCITS}^{1}$ (CESR (2010)). The legislative framework accepts that a variety of models exists for estimating $\mathrm{VaR}$, and that each model has its own set of assumptions, advantages and drawbacks. The common models include the parametric or Variance Covariance or Delta Normal model (DNVaR model), the Historical Simulation model and the Monte Carlo Simulation model. As the CESR explains (CESR (2010), p. 28, Explanatory text 54) “...CESR is of the view that for a UCITS referring largely to financial derivatives presenting non-linear risk features, the parametric VaR model is not appropriate and such a UCITS should rather refer to a Historical Simulation model or a MonteCarlo model.". For the purpose of this study, we will use the most capitalized European stock indices: the German DAX index, the French CAC 40 Index, the UK FTSE Index, the Italian FTSEMIB Index, and the Spanish IBEX Index. Therefore, without using derivatives we will examine our cases adopting the popular, easily applied and easily understood DNVaR model (Jorion (2007)).

In this paragraph we briefly present the CESR (2010) requirements for risk management. According to the CESR (2010, p. 26), the VaR is estimated with the following parameters: (a)

\footnotetext{
${ }^{1}$ Undertakings Collective Investment in Transferable Securities.
} 
one-tailed confidence interval of $99 \%$, and (b) effective observation period (history) of risk factors of at least 1 year (approximately 250 business days) unless a shorter observation period is justified by a significant increase in price volatility (for instance extreme market conditions). The backtest of a VaR model is carried out at least on a monthly basis, and if the number of overshootings for each UCITS for the most recent 250 business days exceeds 4 at the $99 \%$ confidence level (c.l.) the VaR model should be reviewed and the appropriate adjustments should be made (CESR (2010), p. 29-30) ${ }^{2}$. The specific requirements present some deficiencies because it enables risk managers to avoid the cost of adopting advanced models: i.e. in practice, a UCITS may use a conservative and conventional VaR model and a relative VaR approach in order not to exceed the 4 out of the 250 observations limit without encountering any legal problems (Vasileiou (2016)).

This study focuses on the models' evaluation/backtests and their possible consequences. In practice, legislation is exclusively focused on the overshootings issue, without examining whether the VaR estimations are representative of the real financial risk or whether they lead to overreactions and procyclical behavior in the stock market, thus leaving the financial system vulnerable to instability. Moreover, it shows that the more than a year observations limit does not offer anything to the financial system's robustness. The scope of this paper is to reply to questions such as the above mentioned, to highlight deficiencies in the risk regulatory framework, and suggest some legislative adjustments that could contribute to more reliable VaR estimations and a more stable financial environment.

The rest of the paper goes as following: Section 2 presents the theoretical framework and Section 3 empirically validates the study's main assumptions. Section 4 further discusses the findings and shows how the VaR legislative framework is linked to the overreaction and the procyclical behavior of the stock markets. Section 5 concludes the study.

\section{Theoretical framework and Graphical Representation of the Data}

One of the mainstreams and most frequently used models for VaR estimation is the Delta Normal VaR model (DNVaR) or Variance-Covariance model (Jorion (2007), CESR (2010, p.28)). In practice, many UCITS companies, especially small and medium sized, adopt the DNVaR model because it is easily understood, and because of its low-cost implementation (Vasileiou (2016)).

\footnotetext{
2 The Basel Accord suggests three zones of risk depending on the number of violations per 250 observations: the Green zone (up to four violations-accurate model), the yellow zone (5 to 9 violations) and the red zone (more than 10 violations). Less than 4 violations mean the model is accurate. When 5 or more violations are documented it means that there are some doubts regarding its reliability, so penalties are imposed; more than ten violations suggest that the model is completely inaccurate.
} 
The DNVaR model at the $99 \%$ confidence level (c.l.) is estimated as below:

$\mathrm{DNVaR}=($ Expected change in portfolio/asset's value $)$

$-2.33 \times$ (Standard deviation of change in portfolio/asset value)

In a daily process, the mean value (expected returns) is usually considered as zero, which is a reasonable assumption for a short holding period (Linsmeier and Pearson (2000), p. 53), so equation 1 turns to:

$\mathrm{DNVaR}=-2.33 \times($ Standard deviation of change in portfolio/asset value $)$

For the scope of this study, we adopt equation 2 which shows that the standard deviation significantly influences the VaR estimation; but is the 1-year standard deviation representative of the real financial risk? The Efficient Market Hypothesis (EMH) suggests that markets instantly adopt the information into their valuation process (Fama (1970)). Therefore, is the 250-day observation period appropriate for representative VaR estimations or does the increased number of observations lead to estimations that fail to instantly capture the financial trend?

Vasileiou and Pantos (2018) examine the Historical VaR model when the 250-day observation period is used and they provide empirical evidence that the specific model fails to capture the financial trend. Hendricks (1996) suggests that the conventional VaR models that use fewer than 250 observations as inputs (almost a year) present estimations that are closer to the real financial risk conditions than the models that use more than 250 observations (longerobservation models), but they will suffer from many low-deviated overshootings.

Therefore, when the stock market passes from a long-term growth period to a crisis period, the suggested lower limit of 250 observations leads to under-estimated VaRs that fail to notify the risk manager of the upcoming changes in time and any action that could be taken to rectify the situation is at this point ill-advised. The opposite holds when the stock market passes from a crisis period to a growth period. In such a case, the VaR will be much more conservative than the financial environment requires. This investment behavior may lead to procyclicality, which is a less explored issue (Youngman (2008), Adrian and Shin (2013)) than VaR modeling.

The abovementioned cases are presented in Figure 1 using data from the DAX index, the CAC 40 Index, the FTSE Index, the FTSEMIB Index, and the IBEX Index for the period 2002$18^{3}$. Each market is presented in sub-figures (a)-(e), respectively, and each sub-figure shows

\footnotetext{
${ }^{3}$ We use the 2002-2018 period because in 2002 the Euro started to circulate as official currency in the Eurozone countries in our sample (all the sample countries except the UK) which is a significant structural change.
} 


\section{VASILEIOU, SAMITAS Value at Risk}

Figure 1: Conventional VaR Procyclicality, Index Performance, Daily Returns and 1Year Standard Deviation

(a) Germany (DAX)

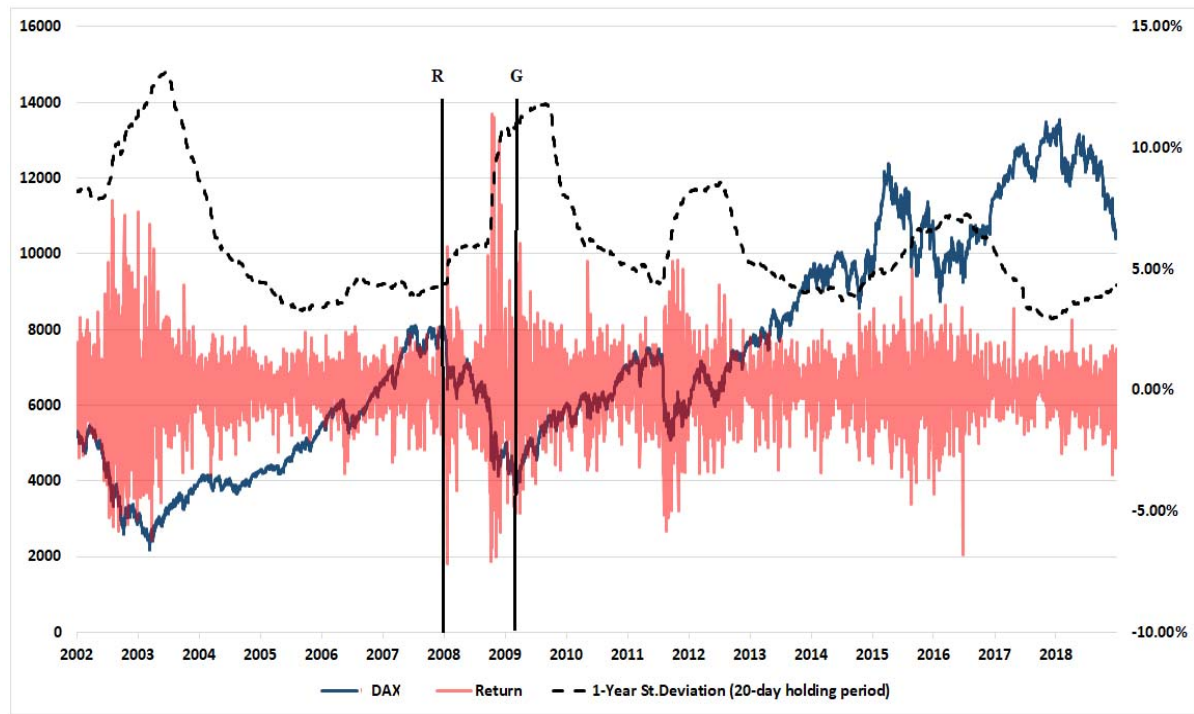

(b) France (CAC 40)

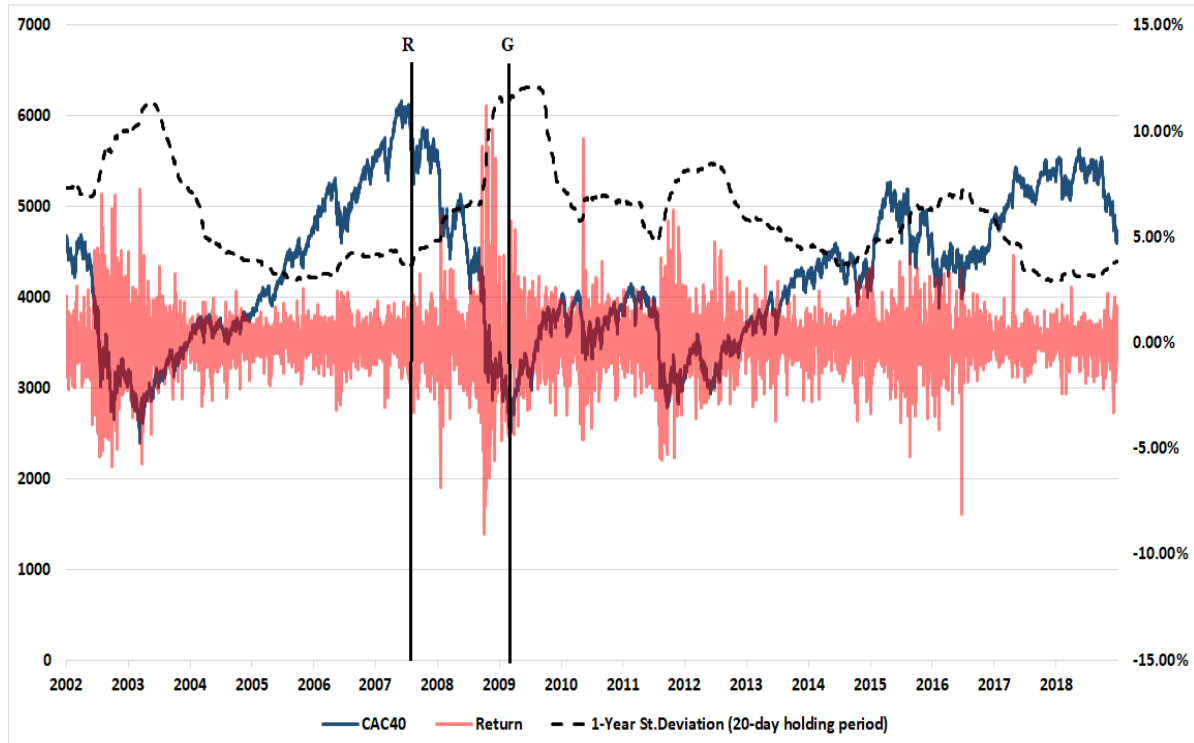


(c) United Kingdom (FTSE)

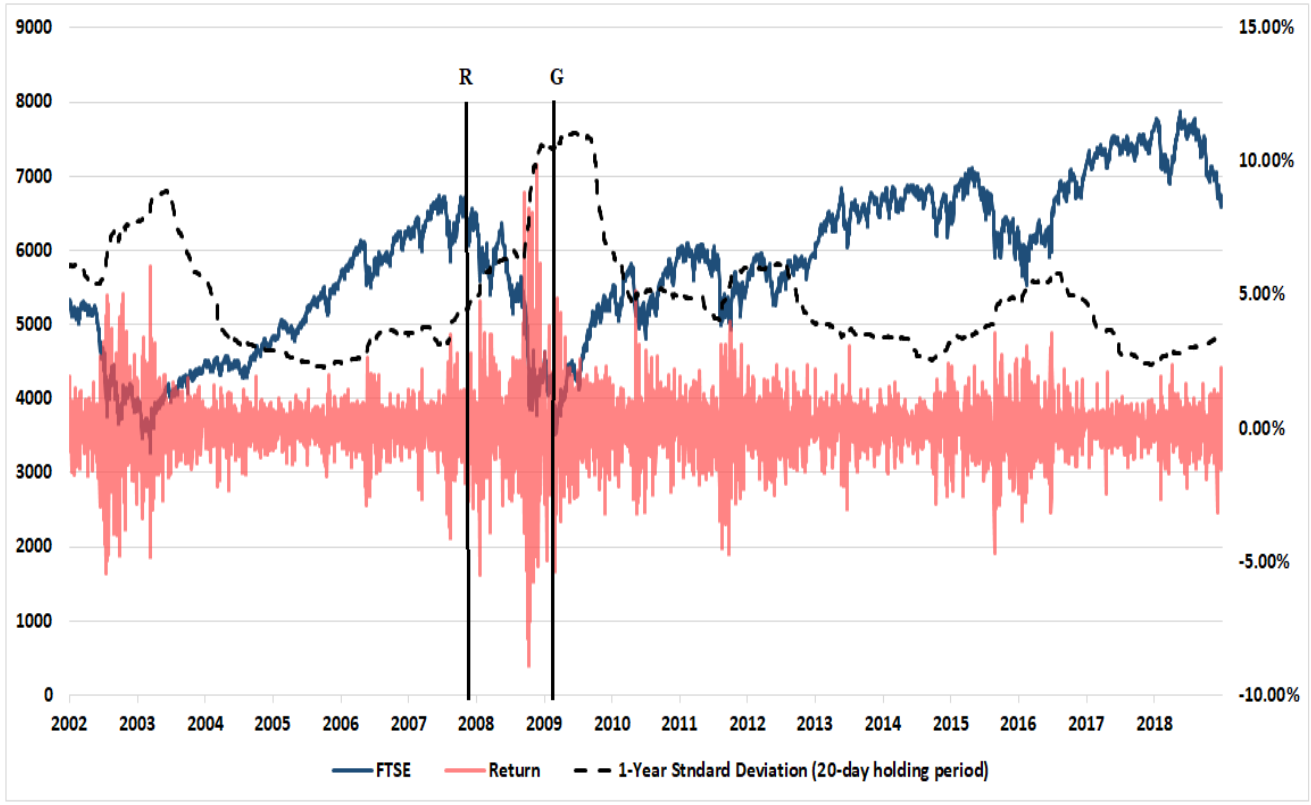

(d) Italy (FTSEMIB)

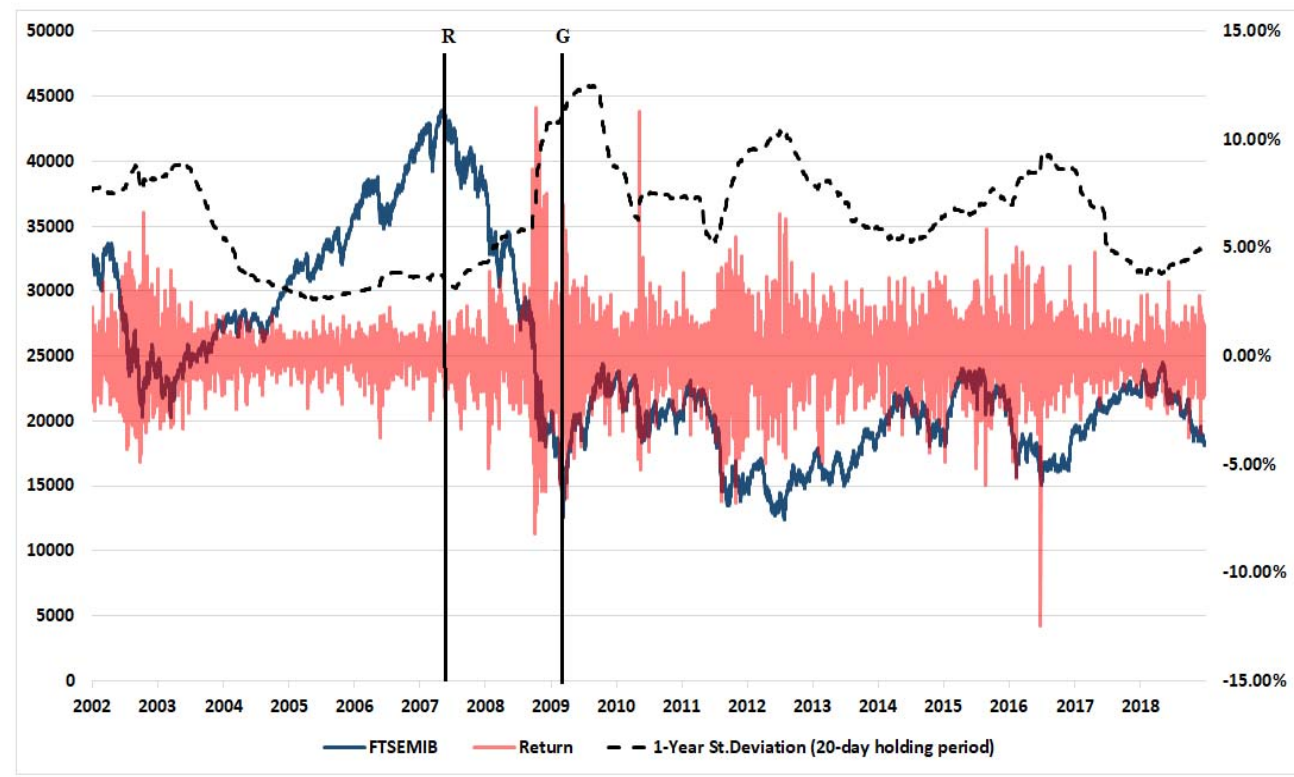




\section{(e) Spain (IBEX)}

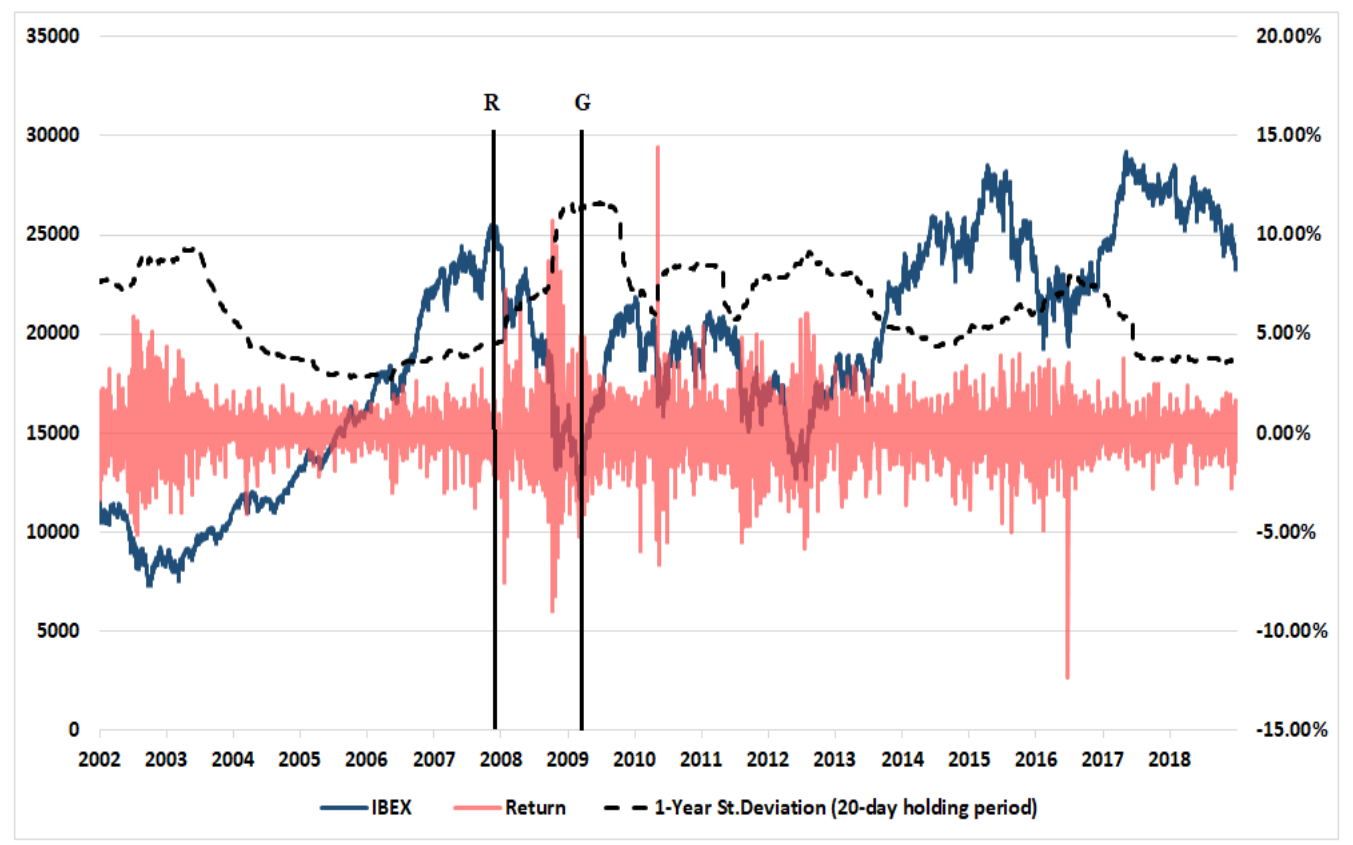

the index performance, the daily returns, and the 1-year Standard Deviation ${ }^{4}$. We observe that when a recession/crisis period comes (points R) the s.d. is lower than when the market turns from recession to growth (points G). This is evidence that the DNVaR method (which is linearly correlated to the s.d., eq. 2) is backward-looking, not representative of the real financial risk, and an indication that it may be a contributory factor to procyclicality. For each market, at point $\mathrm{R}$, the model underestimates the risk, and therefore investors may panic, because the VaR estimation fails to reliably depict the real financial risk. However, after the crisis, point G, the VaR measure over-estimates the risk which may reduce the investor's willingness for new investments, and this behavior may delay the recovery.

The graphical representation shows that the popular DNVaR model (at least 1 Year of data observations) seems to be procyclical when it is evaluated based on current legal guidelines. In point $\mathrm{R}$, the $\mathrm{VaR}$ should increase almost instantly to inform market participants that a crisis/recession is coming. After G, the VaR measure should be lower, because a growth period is coming. As figure 1 shows, the opposite signs are given, because the 250 -observation period does not instantly capture the changing market trends. It is notable that the pattern is robust for

\footnotetext{
${ }^{4}$ We use a 20-day holding period (daily standard deviation multiplied by the square root of 20) in order to show more clearly in the graph (figure 1) that the conventional standard deviation is not an appropriate measure.
} 
all the examined samples, so the procyclicality issue of the VaR estimation under the legislative framework's guidance seems to exist. Therefore, there are signs that the minimum requirement of 250-day observations may lead to procyclical VaR estimations. Is there any test for the procyclicality issue? The reply, is no. However, there are backtesting provisions under the CESR (2010)), which are presented below.

The regulatory framework does not examine at all the VaR estimations' representativeness and procyclicality, because the backtesting procedure only examines the overshootings. This backtesting approach has the following deficiencies:

i.e. assuming that method $\mathrm{A}$ provides a VaR estimation equal to $1 \%$, when the actual losses are $2.5 \%$, this estimation is less accurate than a $2.4 \%$ estimation calculated by method B. However, according to the legislative framework, both models present overshootings. We assume that there is another model $\mathrm{C}$, which is much more conservative than models $\mathrm{A}$ and $\mathrm{B}$, and its VaR estimation equals 4\%. According to the legal guidelines, Model $\mathrm{C}$ is accurate in this case, no matter if the specific model over-estimates the risk. Therefore, we have to question whether or not it is representative.

In an effective financial system the risk should be shared (Allen et al (2004)), and in order for the risk to be shared the VaR estimations should be representative. For a VaR model to be considered as representative and non-procyclical, its estimations should not under-estimate or over-estimate the risk.

Vasileiou and Pantos (2018) observe that the current legislative backtesting procedure is similar to the binomial Kupiec test (1995) which examines the overshootings per a given period in order to conclude whether a model is accurate or not. However, the law requirement for VaR estimations at the $99 \%$ c.l. does not give the opportunity to examine if the VaR models overestimate the risk, which is also against the robustness of the financial system. Particularly, at the $99 \%$ c.l. a model is evaluated as valid when $0-4$ overshootings are observed during the last 250 trading days. When more than 4 violations are observed the model is considered as inaccurate because it underestimates the risk, but when a model over-estimates the risk at this c.l. no sign is given (we cannot have fewer than zero overshootings). Therefore, they suggest that a c.l. lower than $99 \%$ could be adopted. According to the Kupiec (1995) test at the $95 \%$ c.l., the accepted number of overshootings for 250 observations (approximately a year) is between $[7,20]$. More than 20 overshootings show that the model underestimates the risk, and less than 7 is an indicator that the model overestimates the risk.

In this study, we follow the same backtesting procedure as Vasileiou and Pantos (2018) in order to evaluate the models and to examine procyclicality (two backtests at $99 \%$ and $95 \%$ c.l.). Furthermore, we present some simple statistics that could be added to the backtesting procedure in order to present how representative a VaR model is, even when the $99 \%$ c.l. is tested. Moreover, we test the DNVaR model using 250 or more observations (250-, 500- and 750-), and we also test the model using fewer observations than the legislative limit allows (20- and 
125-). The reason is the following: the law requires at least a monthly backtesting of the VaR model. When a model is inaccurate, i.e. the observation period is not appropriate, the model should be revised. Therefore, what does the requirement of at least a 250 -day observation period really offer? If the use of fewer than 250 observations is not appropriate, the observation period can be easily modified following the same procedure that is used to modify/revise longerobservation periods of 250 or more observations. Theoretically, the contribution of a lower limit of observations towards financial stability is minor, but could this limitation have negative effects and lead to procyclical VaR estimations? In the next paragraph, we empirically test these issues.

\section{VaR estimations: What do the Data Say?}

Table 1 presents the empirical results which provide an answer to our abovementioned queries. For each index we present the number of violations per year at the $99 \%$ c.l. and at the $95 \%$ c.l. When a model is considered as inaccurate the cell is shaded for the respective year ${ }^{5}$. The lower part of the tables, which is all shaded, shows some descriptive statistics for a more in-depth analysis that could easily be added to the backtesting procedure in order to test the models' ability to represent the risk. The following measures are included in this part:

- Inaccurate: number of years that the respective model is considered inaccurate, and needs revision. The lower the number the better the VaR model.

- Mean: the mean value of the VaR estimations. As Vasileiou (2016) shows, under the CESR (2010) legislation the risk manager could apply a conservative VaR model and use the relative VaR. This way asset management companies would avoid the adoption of expensive, but accurate and representative VaR estimations programs that use advanced modeling. The lower the number, the less conservative the VaR model.

- Standard Deviation: is the Standard Deviation of the estimated VaR models during the examined period. The higher this number is the more flexible the VaR model is considered (Hendricks (1996), Vasileiou (2017)).

- Min-Max: is the Maximum and the Minimum values of the documented VaR estimation. It is supplementary to the Standard Deviation and the higher the MinMax deviation is the more flexible the VaR model is considered.

- MSE: is the Mean Square Error of the VaR estimations, which is the average squared difference between the estimated $\mathrm{VaR}$ minus the real returns. The lower this number is the more representative to the real data the VaR model is.

\footnotetext{
${ }^{5}$ The violation ranges/areas are: at $99 \%$ more than four overshootings (four overshootings rule), at $95 \%$ the overshootings number should not be between 7 and 20 .
} 
Table 1: Evaluation of DNVaR models.

A. Germany - DAX Index

A1. Germany - DAX Index 99\% c.1.

\begin{tabular}{|c|c|c|c|c|c|}
\hline & $\begin{array}{c}\text { 20-day } \\
\text { DNVaR }\end{array}$ & $\begin{array}{l}\text { 125-day } \\
\text { DNVaR }\end{array}$ & $\begin{array}{l}\text { 250-day } \\
\text { DNVaR }\end{array}$ & $\begin{array}{l}\text { 500-day } \\
\text { DNVaR }\end{array}$ & $\begin{array}{l}\text { 750-day } \\
\text { DNVaR }\end{array}$ \\
\hline 2002 & 1 & 9 & 7 & 15 & 17 \\
\hline 2003 & 2 & 0 & 0 & 1 & 1 \\
\hline 2004 & 5 & 3 & 0 & 0 & 0 \\
\hline 2005 & 4 & 6 & 7 & 0 & 0 \\
\hline 2006 & 7 & 6 & 6 & 7 & 2 \\
\hline 2007 & 5 & 4 & 6 & 6 & 6 \\
\hline 2008 & 8 & 12 & 15 & 18 & 20 \\
\hline 2009 & 3 & 0 & 0 & 4 & 5 \\
\hline 2010 & 5 & 5 & 2 & 0 & 0 \\
\hline 2011 & 9 & 11 & 13 & 12 & 6 \\
\hline 2012 & 3 & 2 & 0 & 0 & 1 \\
\hline 2013 & 6 & 6 & 2 & 0 & 1 \\
\hline 2014 & 9 & 7 & 7 & 6 & 4 \\
\hline 2015 & 8 & 7 & 8 & 13 & 14 \\
\hline 2016 & 3 & 1 & 2 & 3 & 6 \\
\hline 2017 & 3 & 2 & 1 & 0 & 0 \\
\hline 2018 & 7 & 10 & 11 & 9 & 2 \\
\hline Sum of Violations & 88 & 91 & 87 & 94 & 85 \\
\hline Inaccurate & 10 & 10 & 9 & 8 & 7 \\
\hline Mean & $-2.96 \%$ & $-3.11 \%$ & $-3.19 \%$ & $-3.31 \%$ & $-3.41 \%$ \\
\hline $\begin{array}{l}\text { Standard } \\
\text { Deviation }\end{array}$ & $1.67 \%$ & $1.44 \%$ & $1.32 \%$ & $1.09 \%$ & $0.87 \%$ \\
\hline Min & $-12.32 \%$ & $-7.69 \%$ & $-6.82 \%$ & $-5.66 \%$ & $-5.04 \%$ \\
\hline Max & $-0.64 \%$ & $-1.43 \%$ & $-1.52 \%$ & $-1.82 \%$ & $-2.02 \%$ \\
\hline MSE & $0.138 \%$ & $0.140 \%$ & $0.142 \%$ & $0.145 \%$ & $0.147 \%$ \\
\hline $\begin{array}{l}\text { Deviations when } \\
\text { overshootings are } \\
\text { observed (average) }\end{array}$ & $-0.624 \%$ & $-0.763 \%$ & $-0.822 \%$ & $-0.974 \%$ & $-1.067 \%$ \\
\hline
\end{tabular}


VASILEIOU, SAMITAS Value at Risk

A2. Germany - DAX Index 95\% c.l.

\begin{tabular}{|l|c|c|c|c|c|}
\hline & $\begin{array}{c}\text { 20-day } \\
\text { DNVaR }\end{array}$ & $\begin{array}{c}\text { 125-day } \\
\text { DNVaR }\end{array}$ & $\begin{array}{c}\mathbf{2 5 0 - d a y} \\
\text { DNVaR }\end{array}$ & $\begin{array}{c}\text { 500-day } \\
\text { DNVaR }\end{array}$ & $\begin{array}{c}\mathbf{7 5 0} \text {-day } \\
\text { DNVaR }\end{array}$ \\
\hline $\mathbf{2 0 0 2}$ & 21 & 22 & 22 & 28 & 33 \\
\hline $\mathbf{2 0 0 3}$ & 10 & 5 & 4 & 9 & 11 \\
\hline $\mathbf{2 0 0 4}$ & 19 & 9 & 7 & 0 & 0 \\
\hline $\mathbf{2 0 0 5}$ & 13 & 10 & 12 & 7 & 0 \\
\hline $\mathbf{2 0 0 6}$ & 21 & 18 & 20 & 21 & 14 \\
\hline $\mathbf{2 0 0 7}$ & 16 & 15 & 17 & 14 & 20 \\
\hline $\mathbf{2 0 0 8}$ & 20 & 23 & 27 & 36 & 39 \\
\hline $\mathbf{2 0 0 9}$ & 15 & 5 & 5 & 10 & 13 \\
\hline $\mathbf{2 0 1 0}$ & 16 & 11 & 8 & 0 & 3 \\
\hline $\mathbf{2 0 1 1}$ & 23 & 25 & 29 & 30 & 15 \\
\hline $\mathbf{2 0 1 2}$ & 11 & 6 & 4 & 5 & 6 \\
\hline $\mathbf{2 0 1 3}$ & 13 & 14 & 10 & 3 & 5 \\
\hline $\mathbf{2 0 1 4}$ & 22 & 21 & 21 & 18 & 8 \\
\hline $\mathbf{2 0 1 5}$ & 18 & 17 & 22 & 26 & 28 \\
\hline $\mathbf{2 0 1 6}$ & 12 & 9 & 9 & 14 & 15 \\
\hline $\mathbf{2 0 1 7}$ & 12 & 10 & 8 & 0 & 0 \\
\hline $\mathbf{2 0 1 8}$ & 24 & 24 & 30 & 28 & 11 \\
\hline Sum of Violations & 286 & 244 & 255 & 249 & 221 \\
\hline Inaccurate & $\mathbf{5}$ & 8 & 9 & 11 & 9 \\
\hline Mean & $\mathbf{- 2 . 1 0 \%}$ & $-2.20 \%$ & $-2.26 \%$ & $-2.34 \%$ & $-2.41 \%$ \\
\hline $\begin{array}{l}\text { Standard } \\
\text { Deviation }\end{array}$ & $\mathbf{1 . 1 8 \%}$ & $1.02 \%$ & $0.93 \%$ & $0.77 \%$ & $0.62 \%$ \\
\hline Min & $\mathbf{- 8 . 7 1 \%}$ & $-5.44 \%$ & $-4.82 \%$ & $-4.00 \%$ & $-3.56 \%$ \\
\hline Max & $\mathbf{- 0 . 4 6 \%}$ & $-1.01 \%$ & $-1.08 \%$ & $-1.29 \%$ & $-1.43 \%$ \\
\hline MSE & $\mathbf{0 . 0 8 0 \%}$ & $0.081 \%$ & $0.082 \%$ & $0.084 \%$ & $0.085 \%$ \\
\hline $\begin{array}{l}\text { Deviations when } \\
\text { overshootings are } \\
\text { observed (average) }\end{array}$ & $-\mathbf{0 . 6 3 3 \%}$ & $-0.793 \%$ & $-0.789 \%$ & $-0.913 \%$ & $-1.011 \%$ \\
\hline & & & & & \\
\hline
\end{tabular}


B. France-CAC 40 Index

B1. France CAC 40 Index - 99\% c.l.

\begin{tabular}{|l|c|c|c|c|c|}
\hline & $\begin{array}{c}\mathbf{2 0 - d a y} \\
\text { DNVaR }\end{array}$ & $\begin{array}{c}\text { 125-day } \\
\text { DNVaR }\end{array}$ & $\begin{array}{c}\mathbf{2 5 0 - d a y} \\
\text { DNVaR }\end{array}$ & $\begin{array}{c}\text { 500-day } \\
\text { DNVaR }\end{array}$ & $\begin{array}{c}\mathbf{7 5 0} \text {-day } \\
\text { DNVaR }\end{array}$ \\
\hline $\mathbf{2 0 0 2}$ & 2 & 11 & 8 & 15 & 17 \\
\hline $\mathbf{2 0 0 3}$ & 3 & 1 & 0 & 1 & 1 \\
\hline $\mathbf{2 0 0 4}$ & 8 & 5 & 4 & 0 & 0 \\
\hline $\mathbf{2 0 0 5}$ & 5 & 5 & 4 & 1 & 0 \\
\hline $\mathbf{2 0 0 6}$ & 5 & 6 & 7 & 7 & 7 \\
\hline $\mathbf{2 0 0 7}$ & 5 & 6 & 8 & 9 & 11 \\
\hline $\mathbf{2 0 0 8}$ & 5 & 11 & 14 & 20 & 22 \\
\hline $\mathbf{2 0 0 9}$ & 4 & 1 & 0 & 0 & 4 \\
\hline $\mathbf{2 0 1 0}$ & 9 & 6 & 5 & 0 & 2 \\
\hline $\mathbf{2 0 1 1}$ & 6 & 10 & 11 & 10 & 6 \\
\hline $\mathbf{2 0 1 2}$ & 5 & 0 & 0 & 0 & 0 \\
\hline $\mathbf{2 0 1 3}$ & 7 & 4 & 3 & 0 & 1 \\
\hline $\mathbf{2 0 1 4}$ & 9 & 7 & 7 & 7 & 3 \\
\hline $\mathbf{2 0 1 5}$ & 5 & 5 & 8 & 12 & 12 \\
\hline $\mathbf{2 0 1 6}$ & 4 & 2 & 3 & 4 & 5 \\
\hline $\mathbf{2 0 1 7}$ & 3 & 2 & 1 & 0 & 0 \\
\hline $\mathbf{2 0 1 8}$ & 11 & 10 & 9 & 8 & 1 \\
\hline Sum of Violations & 96 & 92 & 92 & 94 & 92 \\
\hline Inaccurate & 12 & 11 & 9 & 8 & 7 \\
\hline Mean & $-\mathbf{2 . 8 9 \%}$ & $-3.03 \%$ & $-3.11 \%$ & $-3.23 \%$ & $-3.31 \%$ \\
\hline $\begin{array}{l}\text { Standard } \\
\text { Deviation }\end{array}$ & $\mathbf{1 . 6 4 \%}$ & $1.37 \%$ & $1.24 \%$ & $1.03 \%$ & $0.82 \%$ \\
\hline Min & $-\mathbf{1 2 . 8 3 \%}$ & $-7.96 \%$ & $-6.30 \%$ & $-5.11 \%$ & $-4.61 \%$ \\
\hline Max & $-\mathbf{0 . 5 9 \%}$ & $-1.29 \%$ & $-1.52 \%$ & $-1.65 \%$ & $-1.88 \%$ \\
\hline MSE & $\mathbf{0 . 1 3 1 \%}$ & $0.132 \%$ & $0.133 \%$ & $0.136 \%$ & $0.138 \%$ \\
\hline $\begin{array}{l}\text { Deviations when } \\
\text { overshootings are } \\
\text { observed (average) }\end{array}$ & $\mathbf{- 0 . 6 2 9 \%}$ & $-0.854 \%$ & $-0.911 \%$ & $-1.018 \%$ & $-1.061 \%$ \\
\hline & & & & & \\
\hline
\end{tabular}


VASILEIOU, SAMITAS Value at Risk

B2. France CAC 40 Index - 95\% c.l.

\begin{tabular}{|l|c|c|c|c|c|}
\hline & $\begin{array}{c}\text { 20-day } \\
\text { DNVaR }\end{array}$ & $\begin{array}{c}\text { 125-day } \\
\text { DNVaR }\end{array}$ & $\begin{array}{c}\text { 250-day } \\
\text { DNVaR }\end{array}$ & $\begin{array}{c}\text { 500-day } \\
\text { DNVaR }\end{array}$ & $\begin{array}{c}\mathbf{7 5 0} \text {-day } \\
\text { DNVaR }\end{array}$ \\
\hline $\mathbf{2 0 0 2}$ & 15 & 20 & 21 & 24 & 26 \\
\hline $\mathbf{2 0 0 3}$ & 12 & 5 & 3 & 6 & 8 \\
\hline $\mathbf{2 0 0 4}$ & 15 & 11 & 9 & 0 & 0 \\
\hline $\mathbf{2 0 0 5}$ & 12 & 11 & 11 & 6 & 0 \\
\hline $\mathbf{2 0 0 6}$ & 17 & 12 & 14 & 17 & 15 \\
\hline $\mathbf{2 0 0 7}$ & 18 & 20 & 23 & 23 & 25 \\
\hline $\mathbf{2 0 0 8}$ & 24 & 22 & 28 & 40 & 47 \\
\hline $\mathbf{2 0 0 9}$ & 16 & 2 & 4 & 7 & 12 \\
\hline $\mathbf{2 0 1 0}$ & 19 & 16 & 16 & 5 & 6 \\
\hline $\mathbf{2 0 1 1}$ & 18 & 22 & 23 & 19 & 14 \\
\hline $\mathbf{2 0 1 2}$ & 14 & 9 & 3 & 9 & 9 \\
\hline $\mathbf{2 0 1 3}$ & 15 & 11 & 8 & 5 & 5 \\
\hline $\mathbf{2 0 1 4}$ & 19 & 18 & 16 & 12 & 7 \\
\hline $\mathbf{2 0 1 5}$ & 16 & 16 & 19 & 23 & 23 \\
\hline $\mathbf{2 0 1 6}$ & 14 & 6 & 9 & 11 & 13 \\
\hline $\mathbf{2 0 1 7}$ & 10 & 7 & 4 & 0 & 0 \\
\hline $\mathbf{2 0 1 8}$ & 21 & 25 & 27 & 22 & 10 \\
\hline Sum of Violations & 275 & 233 & 238 & 229 & 220 \\
\hline Inaccurate & $\mathbf{2}$ & 6 & 9 & 11 & 9 \\
\hline Mean & $\mathbf{- 2 . 0 5 \%}$ & $-2.15 \%$ & $-2.20 \%$ & $-2.28 \%$ & $-2.34 \%$ \\
\hline $\begin{array}{l}\text { Standard } \\
\text { Deviation }\end{array}$ & $\mathbf{1 . 1 6 \%}$ & $0.97 \%$ & $0.87 \%$ & $0.73 \%$ & $0.58 \%$ \\
\hline Min & $\mathbf{- 9 . 0 7 \%}$ & $-5.63 \%$ & $-4.46 \%$ & $-3.61 \%$ & $-3.26 \%$ \\
\hline Max & $\mathbf{- 0 . 4 2 \%}$ & $-0.91 \%$ & $-1.08 \%$ & $-1.17 \%$ & $-1.33 \%$ \\
\hline MSE & $\mathbf{0 . 0 7 6 \%}$ & $0.076 \%$ & $0.077 \%$ & $0.078 \%$ & $0.079 \%$ \\
\hline $\begin{array}{l}\text { Deviations when } \\
\text { overshootings are } \\
\text { observed (average) }\end{array}$ & $-\mathbf{0 . 6 5 7 \%}$ & $-0.875 \%$ & $-0.875 \%$ & $-0.975 \%$ & $-1.032 \%$ \\
\hline & & & & & \\
\hline
\end{tabular}


C. United Kingdom - FTSE

C1. United Kingdom - FTSE 99\% c.1.

\begin{tabular}{|l|c|c|c|c|c|}
\hline & $\begin{array}{c}\mathbf{2 0 - d a y} \\
\text { DNVaR }\end{array}$ & $\begin{array}{c}\text { 125-day } \\
\text { DNVaR }\end{array}$ & $\begin{array}{c}\mathbf{2 5 0 - d a y} \\
\text { DNVaR }\end{array}$ & $\begin{array}{c}\text { 500-day } \\
\text { DNVaR }\end{array}$ & $\begin{array}{c}\mathbf{7 5 0} \text {-day } \\
\text { DNVaR }\end{array}$ \\
\hline $\mathbf{2 0 0 2}$ & 5 & 11 & 11 & 13 & 13 \\
\hline $\mathbf{2 0 0 3}$ & 3 & 1 & 1 & 1 & 2 \\
\hline $\mathbf{2 0 0 4}$ & 6 & 4 & 4 & 0 & 0 \\
\hline $\mathbf{2 0 0 5}$ & 7 & 6 & 4 & 2 & 0 \\
\hline $\mathbf{2 0 0 6}$ & 5 & 6 & 8 & 11 & 9 \\
\hline $\mathbf{2 0 0 7}$ & 7 & 10 & 13 & 11 & 16 \\
\hline $\mathbf{2 0 0 8}$ & 3 & 1 & 0 & 2 & 25 \\
\hline $\mathbf{2 0 0 9}$ & 9 & 6 & 6 & 0 & 0 \\
\hline $\mathbf{2 0 1 0}$ & 7 & 9 & 8 & 7 & 2 \\
\hline $\mathbf{2 0 1 1}$ & 6 & 1 & 0 & 0 & 0 \\
\hline $\mathbf{2 0 1 2}$ & 8 & 4 & 4 & 1 & 1 \\
\hline $\mathbf{2 0 1 3}$ & 11 & 10 & 7 & 5 & 4 \\
\hline $\mathbf{2 0 1 4}$ & 8 & 8 & 9 & 13 & 13 \\
\hline $\mathbf{2 0 1 5}$ & 4 & 2 & 3 & 7 & 7 \\
\hline $\mathbf{2 0 1 6}$ & 4 & 2 & 2 & 1 & 1 \\
\hline $\mathbf{2 0 1 7}$ & 9 & 8 & 9 & 6 & 4 \\
\hline $\mathbf{2 0 1 8}$ & 110 & 97 & 101 & 100 & 99 \\
\hline Sum of Violations & 13 & 10 & 9 & 9 & $\mathbf{6}$ \\
\hline Inaccurate & $-\mathbf{2 . 3 3 \%}$ & $-2.45 \%$ & $-2.51 \%$ & $-2.61 \%$ & $-2.69 \%$ \\
\hline Mean & $\mathbf{1 . 4 1 \%}$ & $1.20 \%$ & $1.09 \%$ & $0.93 \%$ & $0.77 \%$ \\
\hline $\begin{array}{l}\text { Standard } \\
\text { Deviation }\end{array}$ & $-\mathbf{1 1 . 9 5 \%}$ & $-7.27 \%$ & $-5.76 \%$ & $-4.71 \%$ & $-4.15 \%$ \\
\hline Min & $-\mathbf{0 . 5 4 \%}$ & $-1.15 \%$ & $-1.18 \%$ & $-1.34 \%$ & $-1.50 \%$ \\
\hline Max & $\mathbf{0 . 0 8 8 \%}$ & $0.089 \%$ & $0.089 \%$ & $0.091 \%$ & $0.093 \%$ \\
\hline MSE & & & & & \\
\hline $\begin{array}{l}\text { Deviations when } \\
\text { overshottings are } \\
\text { observed (average) }\end{array}$ & $\mathbf{- 0 . 5 0 3 \%}$ & $-0.753 \%$ & $-0.749 \%$ & $-0.918 \%$ & $-0.976 \%$ \\
\hline & & & & & \\
\hline
\end{tabular}


VASILEIOU, SAMITAS Value at Risk

C2. United Kingdom - FTSE 95\% c.l.

\begin{tabular}{|l|c|c|c|c|c|}
\hline & $\begin{array}{c}\mathbf{2 0 - d a y} \\
\text { DNVaR }\end{array}$ & $\begin{array}{c}\text { 125-day } \\
\text { DNVaR }\end{array}$ & $\begin{array}{c}\text { 250-day } \\
\text { DNVaR }\end{array}$ & $\begin{array}{c}\text { 500-day } \\
\text { DNVaR }\end{array}$ & $\begin{array}{c}\text { 750-day } \\
\text { DNVaR }\end{array}$ \\
\hline $\mathbf{2 0 0 2}$ & 25 & 21 & 18 & 21 & 21 \\
\hline $\mathbf{2 0 0 3}$ & 12 & 3 & 2 & 4 & 6 \\
\hline $\mathbf{2 0 0 4}$ & 16 & 11 & 6 & 0 & 0 \\
\hline $\mathbf{2 0 0 5}$ & 14 & 12 & 11 & 9 & 1 \\
\hline $\mathbf{2 0 0 6}$ & 16 & 14 & 15 & 17 & 16 \\
\hline $\mathbf{2 0 0 7}$ & 15 & 19 & 22 & 21 & 25 \\
\hline $\mathbf{2 0 0 8}$ & 20 & 25 & 27 & 34 & 40 \\
\hline $\mathbf{2 0 0 9}$ & 12 & 5 & 3 & 5 & 8 \\
\hline $\mathbf{2 0 1 0}$ & 17 & 13 & 11 & 2 & 2 \\
\hline $\mathbf{2 0 1 1}$ & 20 & 22 & 21 & 18 & 10 \\
\hline $\mathbf{2 0 1 2}$ & 15 & 10 & 3 & 5 & 6 \\
\hline $\mathbf{2 0 1 3}$ & 20 & 13 & 12 & 5 & 4 \\
\hline $\mathbf{2 0 1 4}$ & 21 & 18 & 16 & 12 & 9 \\
\hline $\mathbf{2 0 1 5}$ & 18 & 20 & 21 & 23 & 24 \\
\hline $\mathbf{2 0 1 6}$ & 11 & 6 & 9 & 13 & 14 \\
\hline $\mathbf{2 0 1 7}$ & 14 & 11 & 8 & 1 & 1 \\
\hline $\mathbf{2 0 1 8}$ & 22 & 24 & 28 & 24 & 9 \\
\hline Sum of Violations & 288 & 247 & 233 & 214 & 196 \\
\hline Inaccurate & $\mathbf{3}$ & 7 & 9 & 12 & 11 \\
\hline Mean & $-\mathbf{1 . 6 4 \%}$ & $-1.73 \%$ & $-1.78 \%$ & $-1.84 \%$ & $-1.90 \%$ \\
\hline $\begin{array}{l}\text { Standard } \\
\text { Deviation }\end{array}$ & $\mathbf{1 . 0 0 \%}$ & $0.85 \%$ & $0.77 \%$ & $0.66 \%$ & $0.54 \%$ \\
\hline Min & $\mathbf{- 8 . 4 5 \%}$ & $-5.14 \%$ & $-4.07 \%$ & $-3.33 \%$ & $-2.93 \%$ \\
\hline Max & $-\mathbf{0 . 3 8 \%}$ & $-0.82 \%$ & $-0.83 \%$ & $-0.94 \%$ & $-1.06 \%$ \\
\hline MSE & $\mathbf{0 . 0 5 1 \%}$ & $0.051 \%$ & $0.052 \%$ & $0.052 \%$ & $0.053 \%$ \\
\hline $\begin{array}{l}\text { Deviations when } \\
\text { overshootings are } \\
\text { observed (average) }\end{array}$ & $\mathbf{- 0 . 5 5 3 \%}$ & $-0.695 \%$ & $-0.779 \%$ & $-0.902 \%$ & $-0.982 \%$ \\
\hline & & & & & \\
\hline
\end{tabular}


D. Italy - FTSEMIB Index

D1. Italy - FTSEMIB Index 99\%

\begin{tabular}{|l|c|c|c|c|c|}
\hline & $\begin{array}{c}\mathbf{2 0 - d a y} \\
\text { DNVaR }\end{array}$ & $\begin{array}{c}\text { 125-day } \\
\text { DNVaR }\end{array}$ & $\begin{array}{c}\mathbf{2 5 0 - d a y} \\
\text { DNVaR }\end{array}$ & $\begin{array}{c}\text { 500-day } \\
\text { DNVaR }\end{array}$ & $\begin{array}{c}\mathbf{7 5 0} \text {-day } \\
\text { DNVaR }\end{array}$ \\
\hline $\mathbf{2 0 0 2}$ & 2 & 5 & 3 & 5 & 7 \\
\hline $\mathbf{2 0 0 3}$ & 4 & 0 & 0 & 0 & 0 \\
\hline $\mathbf{2 0 0 4}$ & 6 & 4 & 3 & 0 & 0 \\
\hline $\mathbf{2 0 0 5}$ & 8 & 6 & 7 & 5 & 0 \\
\hline $\mathbf{2 0 0 6}$ & 8 & 6 & 6 & 8 & 6 \\
\hline $\mathbf{2 0 0 7}$ & 9 & 10 & 12 & 11 & 14 \\
\hline $\mathbf{2 0 0 8}$ & 6 & 1 & 16 & 24 & 26 \\
\hline $\mathbf{2 0 0 9}$ & 9 & 6 & 4 & 5 & 8 \\
\hline $\mathbf{2 0 1 0}$ & 6 & 13 & 15 & 13 & 2 \\
\hline $\mathbf{2 0 1 1}$ & 2 & 3 & 0 & 3 & 3 \\
\hline $\mathbf{2 0 1 2}$ & 6 & 2 & 2 & 1 & 2 \\
\hline $\mathbf{2 0 1 3}$ & 7 & 5 & 4 & 3 & 2 \\
\hline $\mathbf{2 0 1 4}$ & 5 & 4 & 4 & 5 & 4 \\
\hline $\mathbf{2 0 1 5}$ & 4 & 4 & 4 & 4 & 6 \\
\hline $\mathbf{2 0 1 6}$ & 5 & 1 & 0 & 0 & 0 \\
\hline $\mathbf{2 0 1 7}$ & 9 & 7 & 11 & 4 & 2 \\
\hline $\mathbf{2 0 1 8}$ & 102 & 89 & 95 & 92 & 89 \\
\hline Sum of Violations & 13 & 9 & 6 & 8 & 7 \\
\hline Inaccurate & $-3.14 \%$ & $-3.29 \%$ & $-3.36 \%$ & $-3.45 \%$ & $-3.50 \%$ \\
\hline Mean & $\mathbf{1 . 6 6 \%}$ & $1.39 \%$ & $1.25 \%$ & $1.05 \%$ & $0.87 \%$ \\
\hline $\begin{array}{l}\text { Standard } \\
\text { Deviation }\end{array}$ & $-\mathbf{- 1 2 . 6 7 \%}$ & $-7.92 \%$ & $-6.50 \%$ & $-5.35 \%$ & $-4.81 \%$ \\
\hline Min & $-\mathbf{0 . 7 1 \%}$ & $-1.16 \%$ & $-1.36 \%$ & $-1.51 \%$ & $-1.65 \%$ \\
\hline Max & $\mathbf{0 . 1 4 9 \%}$ & $0.150 \%$ & $0.152 \%$ & $0.153 \%$ & $0.154 \%$ \\
\hline MSE & & & & & \\
\hline $\begin{array}{l}\text { Deviations when } \\
\text { overshootings are } \\
\text { observed (average) }\end{array}$ & $\mathbf{- 0 . 6 9 \%}$ & $-0.911 \%$ & $-0.959 \%$ & $-1.108 \%$ & $-1.176 \%$ \\
\hline
\end{tabular}


VASILEIOU, SAMITAS Value at Risk

D2. Italy - FTSEMIB Index 95\%

\begin{tabular}{|l|c|c|c|c|c|}
\hline & $\begin{array}{c}\text { 20-day } \\
\text { DNVaR }\end{array}$ & $\begin{array}{c}\text { 125-day } \\
\text { DNVaR }\end{array}$ & $\begin{array}{c}\text { 250-day } \\
\text { DNVaR }\end{array}$ & $\begin{array}{c}\text { 500-day } \\
\text { DNVaR }\end{array}$ & $\begin{array}{c}\text { 750-day } \\
\text { DNVaR }\end{array}$ \\
\hline $\mathbf{2 0 0 2}$ & 17 & 17 & 14 & 20 & 21 \\
\hline $\mathbf{2 0 0 3}$ & 14 & 6 & 3 & 6 & 7 \\
\hline $\mathbf{2 0 0 4}$ & 12 & 10 & 6 & 0 & 0 \\
\hline $\mathbf{2 0 0 5}$ & 14 & 16 & 16 & 8 & 4 \\
\hline $\mathbf{2 0 0 6}$ & 15 & 15 & 19 & 20 & 16 \\
\hline $\mathbf{2 0 0 7}$ & 16 & 22 & 23 & 23 & 24 \\
\hline $\mathbf{2 0 0 8}$ & 29 & 24 & 33 & 43 & 50 \\
\hline $\mathbf{2 0 0 9}$ & 18 & 8 & 7 & 11 & 15 \\
\hline $\mathbf{2 0 1 0}$ & 22 & 18 & 13 & 5 & 10 \\
\hline $\mathbf{2 0 1 1}$ & 19 & 27 & 31 & 29 & 21 \\
\hline $\mathbf{2 0 1 2}$ & 15 & 8 & 6 & 11 & 11 \\
\hline $\mathbf{2 0 1 3}$ & 13 & 12 & 9 & 3 & 6 \\
\hline $\mathbf{2 0 1 4}$ & 15 & 16 & 18 & 14 & 9 \\
\hline $\mathbf{2 0 1 5}$ & 19 & 15 & 13 & 18 & 18 \\
\hline $\mathbf{2 0 1 6}$ & 15 & 10 & 14 & 16 & 19 \\
\hline $\mathbf{2 0 1 7}$ & 16 & 6 & 1 & 1 & 1 \\
\hline $\mathbf{2 0 1 8}$ & 20 & 22 & 29 & 21 & 6 \\
\hline Sum of Violations & 289 & 252 & 255 & 249 & 238 \\
\hline Inaccurate & $\mathbf{2}$ & 6 & 8 & 9 & 9 \\
\hline Mean & $-\mathbf{2 . 2 2} \%$ & $-2.32 \%$ & $-2.37 \%$ & $-2.44 \%$ & $-2.48 \%$ \\
\hline $\begin{array}{l}\text { Standard } \\
\text { Deviation }\end{array}$ & $\mathbf{1 . 1 7 \%}$ & $0.98 \%$ & $0.88 \%$ & $0.74 \%$ & $0.61 \%$ \\
\hline Min & $\mathbf{- 8 . 9 6 \%}$ & $-5.60 \%$ & $-4.60 \%$ & $-3.78 \%$ & $-3.40 \%$ \\
\hline Max & $\mathbf{- 0 . 5 0 \%}$ & $-0.82 \%$ & $-0.96 \%$ & $-1.06 \%$ & $-1.17 \%$ \\
\hline MSE & $\mathbf{0 . 0 8 6 \%}$ & $0.087 \%$ & $0.087 \%$ & $0.088 \%$ & $0.088 \%$ \\
\hline $\begin{array}{l}\text { Deviations when } \\
\text { overshootings are } \\
\text { observed (average) }\end{array}$ & $\mathbf{- 0 . 7 2 1 \%}$ & $-0.865 \%$ & $-0.893 \%$ & $-0.982 \%$ & $-1.026 \%$ \\
\hline & & & & & \\
\hline
\end{tabular}


E. Spain - IBEX Index

E1. Spain - IBEX Index 99\%

\begin{tabular}{|l|c|c|c|c|c|}
\hline & $\begin{array}{c}\mathbf{2 0 - d a y} \\
\text { DNVaR }\end{array}$ & $\begin{array}{c}\text { 125-day } \\
\text { DNVaR }\end{array}$ & $\begin{array}{c}\mathbf{2 5 0 - d a y} \\
\text { DNVaR }\end{array}$ & $\begin{array}{c}\text { 500-day } \\
\text { DNVaR }\end{array}$ & $\begin{array}{c}\mathbf{7 5 0} \text {-day } \\
\text { DNVaR }\end{array}$ \\
\hline $\mathbf{2 0 0 2}$ & 3 & 4 & 4 & 4 & 4 \\
\hline $\mathbf{2 0 0 3}$ & 4 & 1 & 0 & 0 & 0 \\
\hline $\mathbf{2 0 0 4}$ & 7 & 3 & 2 & 1 & 1 \\
\hline $\mathbf{2 0 0 5}$ & 4 & 4 & 2 & 2 & 0 \\
\hline $\mathbf{2 0 0 6}$ & 6 & 7 & 7 & 8 & 6 \\
\hline $\mathbf{2 0 0 7}$ & 9 & 7 & 9 & 10 & 12 \\
\hline $\mathbf{2 0 0 8}$ & 8 & 10 & 13 & 20 & 28 \\
\hline $\mathbf{2 0 0 9}$ & 3 & 0 & 0 & 1 & 4 \\
\hline $\mathbf{2 0 1 0}$ & 9 & 5 & 5 & 4 & 4 \\
\hline $\mathbf{2 0 1 1}$ & 2 & 7 & 8 & 7 & 4 \\
\hline $\mathbf{2 0 1 2}$ & 6 & 3 & 2 & 2 & 3 \\
\hline $\mathbf{2 0 1 3}$ & 5 & 4 & 0 & 0 & 0 \\
\hline $\mathbf{2 0 1 4}$ & 7 & 5 & 5 & 5 & 1 \\
\hline $\mathbf{2 0 1 5}$ & 8 & 5 & 5 & 8 & 7 \\
\hline $\mathbf{2 0 1 6}$ & 2 & 3 & 4 & 4 & 7 \\
\hline $\mathbf{2 0 1 7}$ & 2 & 1 & 1 & 0 & 0 \\
\hline $\mathbf{2 0 1 8}$ & 9 & 6 & 5 & 2 & 1 \\
\hline Sum of Violations & 94 & 75 & 72 & 78 & 82 \\
\hline Inaccurate & 10 & 8 & 8 & 6 & $\mathbf{5}$ \\
\hline Mean & $-\mathbf{2 . 9 9 \%}$ & $-3.15 \%$ & $-3.23 \%$ & $-3.33 \%$ & $-3.40 \%$ \\
\hline $\begin{array}{l}\text { Standard } \\
\text { Deviation }\end{array}$ & $\mathbf{1 . 6 1 \%}$ & $1.31 \%$ & $1.18 \%$ & $1.00 \%$ & $0.82 \%$ \\
\hline Min & $-\mathbf{- 1 2 . 6 3 \%}$ & $-7.47 \%$ & $-6.03 \%$ & $-5.25 \%$ & $-4.82 \%$ \\
\hline Max & $-\mathbf{0 . 8 6 \%}$ & $-1.33 \%$ & $-1.41 \%$ & $-1.49 \%$ & $-1.75 \%$ \\
\hline MSE & $\mathbf{0 . 1 3 8 \%}$ & $0.139 \%$ & $0.141 \%$ & $0.144 \%$ & $0.145 \%$ \\
\hline $\begin{array}{l}\text { Deviations when } \\
\text { overshootings are } \\
\text { observed (average) }\end{array}$ & $\mathbf{- 0 . 7 4 9 \%}$ & $-1.061 \%$ & $-1.157 \%$ & $-1.095 \%$ & $-1.115 \%$ \\
\hline
\end{tabular}


VASILEIOU, SAMITAS Value at Risk

E2. Spain - IBEX Index 95\%

\begin{tabular}{|l|c|c|c|c|c|}
\hline & $\begin{array}{c}\text { 20-day } \\
\text { DNVaR }\end{array}$ & $\begin{array}{c}\text { 125-day } \\
\text { DNVaR }\end{array}$ & $\begin{array}{c}\mathbf{2 5 0 - d a y} \\
\text { DNVaR }\end{array}$ & $\begin{array}{c}\text { 500-day } \\
\text { DNVaR }\end{array}$ & $\begin{array}{c}\mathbf{7 5 0} \text {-day } \\
\text { DNVaR }\end{array}$ \\
\hline $\mathbf{2 0 0 2}$ & 9 & 12 & 12 & 14 & 18 \\
\hline $\mathbf{2 0 0 3}$ & 12 & 5 & 2 & 3 & 3 \\
\hline $\mathbf{2 0 0 4}$ & 13 & 8 & 6 & 1 & 1 \\
\hline $\mathbf{2 0 0 5}$ & 14 & 11 & 8 & 6 & 0 \\
\hline $\mathbf{2 0 0 6}$ & 13 & 12 & 13 & 15 & 12 \\
\hline $\mathbf{2 0 0 7}$ & 17 & 13 & 13 & 19 & 19 \\
\hline $\mathbf{2 0 0 8}$ & 20 & 19 & 27 & 37 & 45 \\
\hline $\mathbf{2 0 0 9}$ & 16 & 4 & 2 & 6 & 8 \\
\hline $\mathbf{2 0 1 0}$ & 20 & 17 & 15 & 7 & 7 \\
\hline $\mathbf{2 0 1 1}$ & 17 & 19 & 18 & 14 & 11 \\
\hline $\mathbf{2 0 1 2}$ & 14 & 16 & 10 & 12 & 14 \\
\hline $\mathbf{2 0 1 3}$ & 13 & 9 & 4 & 4 & 4 \\
\hline $\mathbf{2 0 1 4}$ & 16 & 18 & 17 & 11 & 7 \\
\hline $\mathbf{2 0 1 5}$ & 19 & 12 & 17 & 21 & 17 \\
\hline $\mathbf{2 0 1 6}$ & 16 & 9 & 13 & 14 & 17 \\
\hline $\mathbf{2 0 1 7}$ & 15 & 8 & 4 & 1 & 1 \\
\hline $\mathbf{2 0 1 8}$ & 25 & 19 & 17 & 14 & 6 \\
\hline Sum of Violations & 269 & 211 & 198 & 199 & 190 \\
\hline Inaccurate & $\mathbf{1}$ & 2 & 6 & 8 & 7 \\
\hline Mean & $\mathbf{- 2 . 1 1 \%}$ & $-2.23 \%$ & $-2.28 \%$ & $-2.35 \%$ & $-2.40 \%$ \\
\hline $\begin{array}{l}\text { Standard } \\
\text { Deviation }\end{array}$ & $\mathbf{1 . 1 4 \%}$ & $0.93 \%$ & $0.83 \%$ & $0.70 \%$ & $0.58 \%$ \\
\hline Min & $\mathbf{- 8 . 9 3 \%}$ & $-5.28 \%$ & $-4.27 \%$ & $-3.71 \%$ & $-3.41 \%$ \\
\hline Max & $\mathbf{- 0 . 6 1 \%}$ & $-0.94 \%$ & $-1.00 \%$ & $-1.05 \%$ & $-1.24 \%$ \\
\hline MSE & $\mathbf{0 . 0 8 0 \%}$ & $0.081 \%$ & $0.081 \%$ & $0.083 \%$ & $0.084 \%$ \\
\hline $\begin{array}{l}\text { Deviations when } \\
\text { overshootings are } \\
\text { observed (average) }\end{array}$ & $-\mathbf{0 . 6 9 5 \%}$ & $-0.899 \%$ & $-0.962 \%$ & $-1.005 \%$ & $-1.087 \%$ \\
\hline & & & & & \\
\hline & & & & & \\
\hline
\end{tabular}

- Deviations when overshootings are observed (average): is the average value of the deviations between the VaR estimation and the losses when a deviation is observed. The lower this number is the closer to the real risk the VaR model is. As it has been mentioned, the legislative framework examines only the number of violations. This 
simple statistical measure could contribute to more representative VaR estimations, especially at the $99 \%$ c. 1 .

The results are presented in Table 1 and the best values from each category, according to the above-mentioned criteria, are indicated with bold numbers. We analytically present the way the models were evaluated taking as a basic example the German stock market and the DAX Index ${ }^{6}$. The conclusions of the other examined cases are similar to those presented below for the German case.

As the results show at the $99 \%$ c.l. the 750 -day DNVaR is considered the most accurate because it is deemed inaccurate in only 7 backtests according to the four overshootings rule. If we examine the results more closely, we observe that the model is marginally inaccurate in 2007, 2009, 2011 and 2016, because in those years up to six overshootings per year were documented, which means that the modelling issue is not so severe. When the specific model presents significant accuracy issues such as in 2002, 2008 and 2015, the model should be revised using a shorter observation period, as the law suggests. This way the financial risk is manageable and the asset management companies may avoid bearing the cost of adopting advanced models (Vasileiou (2016)).

However, if we do not restrict our evaluation only to the number of overshootings, we observe that the specific version of the DNVaR model is the most conservative (compare the Mean values) and the less flexible to adopt the changes in the financial environment (compare Standard Deviations, Min, Max and MSE values). Finally, when overshootings are observed there are too many per year (20 in 2008, at the $99 \%$ c.l.) and highly deviated from the real losses (the VaR estimations fail on average $1.067 \%$ relative to the real losses per day). At the same confidence level, the 20-day DNVaR model even though it is considered inaccurate in 10 out of the 17 years, the statistics show that it is the most representative of the real financial risk amongst the examined. It is the least conservative, the most flexible to capture the real financial risk, it presents the lowest MSE, and when overshootings are observed the VaR estimations are closer to the real losses. However, according to the four overshootings rule this model is amongst the least accurate, because the law does not examine whether the models are representative of the real financial risk and/or whether they cause procyclicality. Therefore, some supplementary statistics like those reported above could be useful for examining how representative the VaR estimations are at the $99 \%$ c.l..

Taking into consideration the abovementioned, we tried to find a way to test whether the 750day DNVaR model is the most accurate or the most conservative. An additional evaluation procedure at a confidence level lower than $99 \%$ may be a solution for more accurate and non procyclical VaR estimations (Vasileiou and Pantos (2018)). We examine the same models at

\footnotetext{
${ }^{6}$ There is no specific reason as to why we present the German case. As the results show, we would reach similar conclusions if we were to choose any other market in our sample.
} 


\section{VASILEIOU, SAMITAS Value at Risk}

the $95 \%$ c.l. which allows us to evaluate whether a model overestimates or underestimates the risk

The results are presented in the second sub-Table A2 for the German case, and show that: (i) the 20-day DNVaR model is the most accurate amongst the examined models, because it is considered inaccurate only 1 out of the 17 years, and (ii) when overshootings are observed the deviations from the real losses are lower than those documented in the other models. The 750day DNVaR model overestimates the risk in 6 out of the 17 years $(2004,2005,2010,2012$, 2013 and 2017) and underestimates the risk in 3 out of the 17 years (2002, 2008 and 2015) which are indications for procylicality and this is not in favor of the robustness of the financial system. Therefore, at the $95 \%$ c.l. the increased number of years that the 750 -day DNVaR is considered inaccurate due to over-estimation reasons may be an indication that the model at the $99 \%$ c.l. was the most accurate not because it representatively captures the financial risk, but because the specific model was conservative.

Similar analysis could be done for the rest of the markets/cases we have examined in this study. All these findings are contemporary validations of Hendricks' (1996) conclusions that

- the conventional VaR models that use a recent/short-term observation period present an increased number of low deviated violations, which is true when we compare the short-length $(=<250$ observations $)$ versus the longer-observation $(>250)$ models, but

- the short-length VaR models are more representative of the real financial conditions than the long-VaR models, as the respective tables at the $95 \%$ c.l. show. The shorter-length models are considered as inaccurate significantly fewer times than the longer-observation CDNVaR models.

\section{Further Discussion}

The empirical findings show some legislative deficiencies that need to be addressed in order to make the financial system stronger. The law can be easily amended in the following ways to achieve greater stability:

a. the c.1. at $99 \%$ examines if the VaR underestimates the risk, but it does not examine if the VaR overestimates the risk; therefore an extra backtesting procedure at a lower c.l. could prove useful in order to resolve the specific issue that may lead to procyclicality. Moreover, some VaR statistics, similar to those reported in the lower shaded part in Table 1, can be used to test the reliability and representativeness of VaR models (especially at the $99 \%$ c.1.), and

b. the limitation of 250 observations at least for the data inputs number does not offer something to the robustness of the financial system. On the contrary, it may lead to specific risk management practices that contribute to procyclical and conservative 
VaR estimations which meet the legal requirements but fail to accurately assess risk.

Many distinguished researchers stress that the financial markets overreact and that the economy is cyclical (Bernanke (1983), De Bondt and Thaler (1985, 1990), Schwert (1989)). Several explanations have been proposed as to why this happens. This paper presents an alternative view based on a structural/legal justification of the possible reasons that could contribute to market overreaction and procyclicality. At points such as R (Figure 1), stock holders may bear increased risk, but the VaR estimations do not warn them. Consequently, when the crisis emerges, losses higher than those expected prompt stock holders to try to sell their positions and this may lead to sharp decline (overreactions). On the other hand, in points similar to G, when the stock market recovers, investors may not be able to bear increased risk because the VaR measures incorrectly predict higher risk and behavioral and/or legal restrictions ${ }^{7}$ may influence their decision. Such an investment behavior in points similar to $\mathrm{R}$ and $\mathrm{G}$ contributes to the market's procyclicality, which is not a favorable factor for a robust financial system.

The CESR (2010) presents similarities to the Basel Accords, because in most of the cases asset management legislation adopts the Basel requirements ${ }^{8}$. Therefore, it is worth mentioning that a consultation paper by the Basel Committee on Banking Supervision (2013, p. 3) has confirmed its intention to move from the VaR to Expected Shortfall (ES). The reason for this change according to this report is "A number of weaknesses have been identified with using VaR for determining regulatory capital requirements, including its inability to capture "tail risk"'. Concerns about the adoption of VaR as the fundamental risk measure have long been raised, even from a theoretical perspective (see Artzner, Delbaen, Eber, and Heath (1999)) and the problem of risk underestimation/tail risk is not new. However, as Acerbi and Szekely (2014) note, the Basel Committee (BCBS (2013)) still uses the VaR as a backtesting measure for internal risk.

Therefore, scholars and financial engineers should try to formulate easy to understand and easy to apply VaR models, which do not suffer so much from tail risk. The legislative framework should force investment companies to stop using risk management practices that are designed to avoid legal restrictions and instead to invest on VaR systems for accurate and representative risk estimation. Moreover, even if the VaR models are replaced by the ES models, when these models are backtested they should provide not only accurate but also representative risk estimations of the examined financial conditions. If the risk measures

\footnotetext{
${ }^{7}$ Investments which are limited by an absolute VaR threshold (CESR 2010, p. 26) may not be able to bear increased risk during recovery because $\mathrm{VaR}$ at $\mathrm{G}$ point is increased.

${ }^{8}$ Recently a new legislative framework for Money Market Funds has been adopted, and ESMA mentions (2018), p.24) that the liquidity stress tests are based on Basel 3 Liquidity Coverage Ratio.
} 


\section{VASILEIOU, SAMITAS Value at Risk}

instantly capture the real risk, this will lead to a more effective and robust financial system, because panic will be reduced ${ }^{9}$. Furthermore, the VaR measures should be presented not only in the annual reports, but at least on a monthly basis in order to inform the investors of the risk they bear.

\section{Conclusions}

We highlight some deficiencies of the VaR legislative framework, and we propose that scholars, regulators, and researchers should find a way to turn VaR from a conventional and backwardlooking statistical measure to a significant indicator for the stability of the financial market. Conventional VaR models not only fail to provide information for financial trend changes, but also contribute to such phenomena as procyclicalitycyclicity and overreaction in the stock market.

Therefore, the legislative framework should force financial companies to use models that provide not only accurate but also representative VaR estimations. We suggest some simple interventions and additional tests that could contribute to this, such as: (a) detailed VaR statistics that show how representative the VaR estimations are, (b) an extra backtesting procedure at a confidence level lower than $99 \%$ that the law proposes, in order to show not only when the models under-estimate the risk, but also when the models over-estimate the risk, so as to reduce the procyclicality issue. Moreover, we provide empirical evidence that the legal guideline on input data which requires at least 250 observations may not lead to more representative VaR estimations. As we presented, this limitation does not contribute to the stability of the financial system, and therefore it should be removed.

The authorities should focus on the tradeoff between an increased number of overshootings that present lower deviations and a lower number of overshootings that present higher deviations. At the same time, scholars and financial engineers should find easily applied and understood models that provide VaR estimations which are as accurate and as representative as those calculated by advanced VaR models.

\section{References}

Acerbi, C., \& Szekely, B. (2014). Back-testing expected shortfall. Risk, 27(11), 76-81.

Adrian, T., \& Shin, H. S. (2013). Procyclical leverage and value-at-risk. Review of Financial Studies, 27(2), 373-403.

Allen, F., Chui, M. K., \& Maddaloni, A. (2004). Financial Systems in Europe, the USA, and ASIA. Oxford Review of Economic Policy, 20(4), 490-508.

\footnotetext{
${ }^{9}$ At it has been mentioned, if a VaR model significantly underestimates the risk i.e. VaR $1 \%$ and losses $2.5 \%$, this may lead to panic because the risk is not representative. After a crisis the VaR should not be overestimated in order not to panic the investors when the recovery period comes.
} 
Artzner, P., Delbaen, F., Eber, J. M., \& Heath, D. (1999). Coherent measures of risk. Mathematical Finance, 9(3), 203-228.

Basle Committee on Banking Supervision (BCBS, 1996). Supervisory framework for the use of back testing in conjunction with the internal models approach to market risk capital requirements, Bank for International Settlements, Basle Report n.22.

Basel Committee on Banking Supervision (BCBS, 2013) Fundamental review of the trading book: a revised market risk framework. In: Second Consultative Paper.

Beck, T., Levine, R., \& Loayza, N. (2000). Finance and the Sources of Growth. Journal of Financial Economics, 58(1-2), 261-300.

Bernanke, B. S. (1983). Irreversibility, uncertainty, and cyclical investment. Quarterly Journal of Economics, 98(1), 85-106.

Billio, M., \& Pelizzon, L. (2000). Value-at-risk: a multivariate switching regime approach. Journal of Empirical Finance, 7(5), 531-554.

Committee of European Securities Regulators (CESR 2010), CESR's Guidelines on Risk Measurement and the Calculation of Global Exposure and Counterparty Risk for UCITS. CESR/10-788.

De Bondt, W. F., \& Thaler, R. (1985). Does the stock market overreact?. Journal of Finance, 40(3), 793-805.

De Bondt, W. F., \& Thaler, R. H. (1990). Do security analysts overreact?. American Economic Review, 52-57.

Engle, R. F., \& Manganelli, S. (2004). CAViaR: Conditional autoregressive value at risk by regression quantiles. Journal of Business \& Economic Statistics, 22(4), 367-381.

European Securities and Markets Authority (ESMA, 2018). Draft guidelines on stress test scenarios under the MMF Regulation. ESMA 34-49-131

Fama, E. F. (1995). Random walks in stock market prices. Financial Analysts Journal, 51(1), 75-80.

Hendricks, D. (1996). Evaluation of value-at-risk models using historical data. Economic Policy Review, (Apr), 39-69.

Jiménez-Martín, J. Á., McAleer, M., \& Pérez-Amaral, T. (2009). The ten commandments for managing value at risk under the basel ii accord. Journal of Economic Surveys, 23(5), 850855.

Jorion, P. (2007). Financial Risk Manager Handbook (Vol. 406). John Wiley \& Sons.

Kupiec, P. H. (1995). Techniques for verifying the accuracy of risk measurement models. Journal of Derivatives, 3(2), 73-84.

Linsmeier, T. J., \& Pearson, N. D. (2000). Value at risk. Financial Analysts Journal, 56(2), 4767.

Liu, S., \& Tse, Y. K. (2015). Intraday Value-at-Risk: an asymmetric autoregressive conditional duration approach. Journal of Econometrics, 189(2), 437-446. 
Moussa, A. M., Kamdem, J. S., \& Terraza, M. (2014). Fuzzy value-at-risk and expected shortfall for portfolios with heavy-tailed returns. Economic Modelling, 39, 247-256.

Reinhart, C. M., \& Rogoff, K. S. (2008). Is the 2007 US sub-prime financial crisis so different? An international historical comparison. American Economic Review, 98(2), 339-44.

Ross, S. A. (1993, October). Is beta useful?. In AIMR Conference Proceedings (Vol. 1993, No. 6, pp. 11-15). Association for Investment Management and Research.

Schwert, G. W. (1989). Why does stock market volatility change over time? Journal of Finance, 44(5), 1115-1153.

Vasileiou, E. (2016). Overview of the Greek value at risk (VaR) legislation framework: Deficiencies, proposals for future revision and a new suggested method. Journal of Financial Regulation and Compliance, 24(2), 213-226.

Vasileiou, E. (2017) Value at Risk (VaR) Historical Approach: Could It Be More Historical and Representative of the Real Financial Risk Environment? Theoretical Economics Letters, 7, 951-974.

Vasileiou, E., \& Pantos, T. D. (2018). What Do the Value at Risk Measure and the Respective Legislative Framework Really Offer to Financial Stability? Critical Views and Procyclicality. forthcoming in European Journal of Economics and Economic Policies: Intervention.

Youngman, P. (2009). Procyclicality and value at risk. In Bank of Canada Financial System Review, June

Zhang, H. G., Su, C. W., Song, Y., Qiu, S., Xiao, R., \& Su, F. (2017). Calculating Value-atRisk for high-dimensional time series using a nonlinear random mapping model. Economic Modelling, 67, 355-367. 